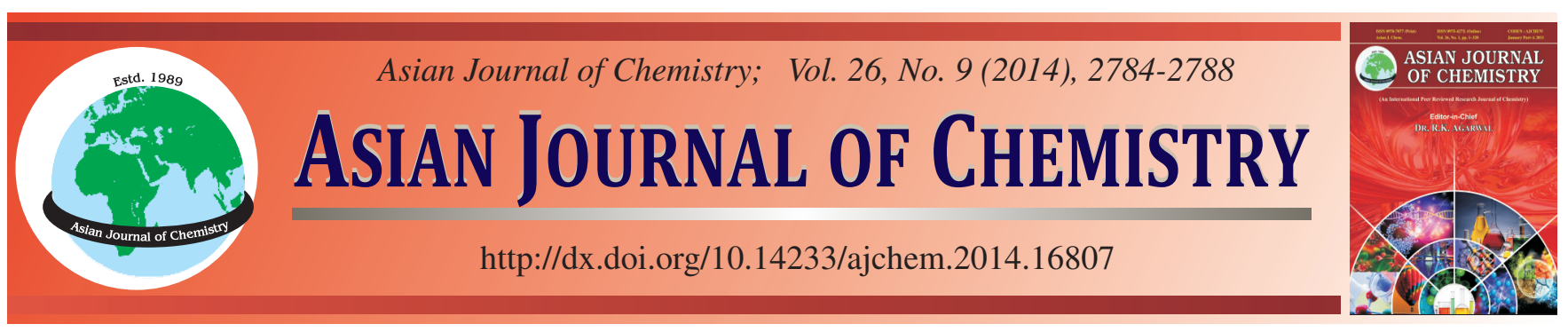

\title{
Homogeneous Gas-Phase Formation Mechanism of Emerging Organic Pollutants Polyfluorinated Dibenzo-p-dioxins and Dibenzofurans from 2-Fluorophenol
}

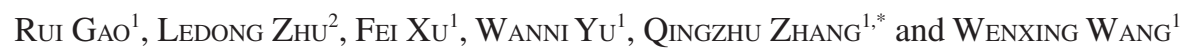

${ }^{1}$ Environment Research Institute, Shandong University, Jinan, P.R. China

${ }^{2}$ School of Chemistry and Chemical Engineering, Shandong University, Jinan, P.R. China

*Corresponding author: Fax: +86 531 88361990; Tel: +86 531 88369788; E-mail: zqz@ sdu.edu.cn

Accepted: 17 February 2014;

Published online: 28 April 2014;

AJC-15119

The emerging organic pollutants polyfluorinated dibenzo- $p$-dioxins and dibenzofurans (PFDD/Fs) have attracted wide attention in environmental and toxicological effects. Here, based on the results of density functional theory (DFT) calculations, we present detailed insight into the formation mechanism of polyfluorinated dibenzo- $p$-dioxins and dibenzofurans. Fluorophenols are recognized as precursors of polyfluorinated dibenzo- $p$-dioxins and dibenzofurans. Using the simple structure 2-fluorophenol as model precursor, the formation mechanism of polyfluorinated dibenzo- $p$-dioxins and dibenzofurans was investigated. Thermodynamic and kinetic analysis suggested that only the pathways with no C-F bond breaking are thermodynamically favorable. The possible formation mechanism is compared with formation mechanism of polychlorinated dibenzo- $p$-dioxin/dibenzofurans and polybrominated dibenzo- $p$-dioxins and dibenzofurans in the previous literature. The rate constants and their temperature dependence of the crucial elementary reactions are calculated by canonical variation transition-state theory with the small curvature tunneling contribution over the temperature range of $600-1200 \mathrm{~K}$. The calculated results may help to improve our understanding for the formation mechanism of polyfluorinated dibenzo- $p$-dioxins and dibenzofurans and be informative to environmental scientists.

Keywords: Polyfluorinated dibenzo-p-dioxins, Polyfluorinated dibenzofurans, Fluorophenols.

\section{INTRODUCTION}

As emerging organic pollutants, polyfluorinated dibenzo$p$-dioxins and dibenzofurans (PFDD/Fs) have been observed both in laboratory investigation ${ }^{1}$ and in collected samples from waste incineration of organ-fluorine containing compounds ${ }^{2}$. The dioxins are considered to be the major family of persistent organic pollutants (POPs) with the effect of carcinogenic, teratogenic, and mutagenic. The $\mathrm{PFDD} / \mathrm{Fs}$ are fluorinated congeners which analogous to the polychlorinated dibenzo$p$-dioxin/dibenzofurans (PCDD/Fs) and polybrominated dibenzo- $p$-dioxin/dibenzofurans (PBDD/Fs). Thus, they may result in serious environmental pollution and effect on human health and attract widespread concern of scientists and the public $^{3-8}$. Herzke et al. ${ }^{9}$ have measured the distribution and concentration of $\mathrm{PFDD} / \mathrm{Fs}$ in Wistar rats' tissue, and revealed that $\mathrm{PFDD} / \mathrm{Fs}$ are less toxic than $\mathrm{PCDD} / \mathrm{Fs}$ and $\mathrm{PBDD} / \mathrm{Fs}$. However, they declared that the situation might be more complex in human, and the data in rat could not exclude the probability of a massive exposure to huge and multiple doses of PFDD/Fs might induce adverse effects on human being. Fluorine-containing materials have been widely used in industrial production and daily life industry due to their high- performance in chemical and thermal inertness, low surface energy, and high surface-active properties, such as fluorinated ethylene propylene and liquid crystal display $(\mathrm{LCD})^{10,11}$. The principal origin of dioxins is combustion processes, especially those of municipal solid waste in incinerators ${ }^{12-14}$. Along with the increasing use of fluorine materials, studies need pay more attention to the possible formation of $\mathrm{PFDD} / \mathrm{Fs}^{5,15-17}$.

Polyfluorinated dibenzo- $p$-dioxins and dibenzofurans are considered to have the similar formation mechanism with PCDD/Fs and PBDD/Fs. Chlorophenols (CPs) and bromophenols (BPs) were demonstrated to be the direct precursors of dioxins. Thus, PFDD/Fs can be predicted to be formed from fluorophenols (FPs) in the municipal waste incinerators (MWIs) or other high temperature industry processes. Several studies on dioxins formation from Chlorophenols and bromophenols have been reported in the previous works ${ }^{18-20}$. Compared with PCDD/Fs and PBDD/Fs, the studies on the formation of PFDD/ Fs are relatively rare. In this work, the formation mechanism of PFDD/Fs from fluorophenols is investigated by using direct density functional theory (DFT). And, the rate constants of elementary reactions involved in the formation of PFDD/Fs were evaluated. 


\section{COMPUTATIONAL METHODS}

The DFT calculations were performed using the Gaussian 03 package on Dell workstation. All geometrical parameters (reactants, transition states, intermediates and products) were fully optimized at the MPWB1K level of theory with a standard $6-31+G(d, p)$ basis set. The MPWB1K method has excellent performance in thermochemistry and thermochemical kinetics $^{21,22}$, and this method has been successfully used in the studies of PCDD and PBDD formations ${ }^{23,24}$. The nature of various stationary points was determined by frequency calculations. To check whether the obtained transition states connect the right minima, the intrinsic reaction coordinate (IRC) calculations were carried out at the MPWB1K/6-31+G(d,p) level. The minimum energy paths (MEPs) were obtained in mass-weighted Cartesian coordinates. The single-point energy calculations were carried out at the MPWB1K/6-311+G (3df,2p) level on the basis of the MPWB1K/6-31+G(d,p) optimized geometries to yield more accurate energetic information.

The theoretical rate constants and their temperature dependence were calculated by using the Polyrate 9.3 program with the aid of canonical variational transition-state theory $(\mathrm{CVT})^{25,26}$. The transmission coefficient was calculated by the smallcurvature tunneling (SCT) method, based on the centrifugaldominant small-curvature semi-classical adiabatic ground-state approximation $^{27}$.

\section{RESULTS AND DISCUSSION}

Previous studies showed that MPWB1K is an effective and accuracy method in the calculation of transition state geometries. The calculated data of phenol and dibenzo- $p$-dioxin (DD) agreed well with experimental results. The geometries and vibrational frequencies of phenol and dibenzo- $p$-dioxin calculated at the MPWB1K/6-311+G(3dp,2p) level are agreed well with the experimental values ${ }^{28-30}$, and the relative error remains within $1.5 \%$ for the geometrical parameters. Yang et al. ${ }^{7}$ obtained several thermodynamic properties (standard enthalpy $\left(\Delta \mathrm{H}_{\mathrm{f}}{ }^{0}\right)$ and the Gibbs free energy of formation $\left(\Delta \mathrm{G}_{\mathrm{f}}^{0}\right)$ ) of PFDDs by DFT calculations at the 6-311G(d) level and the values were consistent with experimental results.

Formation of 2-fluorophenoxy radicals: Previous works have shown that PCDD/Fs and PBDD/Fs are primarily formed by the dimerization of chlorophenoxy radicals and bromophenoxy radicals. Thus, the dimerization of fluorophenoxy radicals (FPRs) can be predicted to be the initial step in the formation of PFDD/Fs. In the municipal waste incinerators or other high temperature industry processes, 2-fluorophenoxy radicals can be formed from fluorophenols through loss of the phenoxyl-hydrogen via unimolecular, bimolecular, or possibly other low-energy pathways (including heterogeneous reactions). In the combustion environment, the unimolecular reaction includes the decomposition of 2-fluorophenol with the cleavage of the $\mathrm{O}-\mathrm{H}$ bond, and the bimolecular reaction includes attack by atomic $\mathrm{H}, \mathrm{OH}$ radical, $\mathrm{O}\left({ }^{3} \mathrm{P}\right)$ and halogen atoms, etc. The potential barriers $(\Delta \mathrm{E})$ and reaction heats $(\Delta \mathrm{H}, 0 \mathrm{~K})$ were calculated at the MPWB1K/6-311+G(3dp, $2 \mathrm{p})$ level.

\section{2-FP $\rightarrow$ 2-FPR $+\mathrm{H} \quad$ barrierless}

$2-\mathrm{FP}+\mathrm{H} \rightarrow 2-\mathrm{FPR}+\mathrm{H}$

$\Delta \mathrm{H}=84.45 \mathrm{kcal} / \mathrm{mol}(1)$
$\Delta \mathrm{H}=-13.48 \mathrm{kcal} / \mathrm{mol}(2)$
$2-\mathrm{FP}+\mathrm{OH} \rightarrow 2-\mathrm{FPR}+\mathrm{H}_{2} \mathrm{O} \quad \Delta \mathrm{E}=1.71 \mathrm{kcal} / \mathrm{mol}$ $\Delta \mathrm{H}=-13.09 \mathrm{kcal} / \mathrm{mol}(3)$

$2-\mathrm{FP}+\mathrm{O}\left({ }^{3} \mathrm{P}\right) \rightarrow 2-\mathrm{FPR}+\mathrm{OH}$ barrierless

$\Delta \mathrm{H}=-78.59 \mathrm{kcal} / \mathrm{mol}(4)$

2-FP $+\mathrm{Cl} \rightarrow 2-\mathrm{FPR}+\mathrm{HCl}$ barrierless

$\Delta \mathrm{H}=-33.98 \mathrm{kcal} / \mathrm{mol}(5)$

2-FP $+\mathrm{F} \rightarrow 2-\mathrm{FPR}+\mathrm{HF} \quad$ barrierless

$\Delta \mathrm{H}=-44.87 \mathrm{kcal} / \mathrm{mol}(6)$

Formation of PFDDs from 2-fluorophenoxy radical dimerization: Four PFDD congeners, dibenzo- $p$-dioxin, 1MFDD, 1,6-DFDD, and 1,9-DFDD, can be formed from the dimerization of 2-fluorophenoxy radicals. Six possible formation pathways are depicted in Fig. 1. As shown in Fig. 1, all PFDD formation pathways start with oxygen-carbon coupling, followed by $\mathrm{F}$ or $\mathrm{H}$ abstraction, ring closure, and intra-annular elimination of F or H. Noted that there is a Smiles rearrangement after $\mathrm{H}$ abstraction in pathways 5 and 6 . The dimerization of 2-fluorophenoxy radicals is a barrierless and strongly exothermic process. The $\mathrm{H}$ abstraction steps are highly exothermic and have low-energy barriers. In the pathways 1 , 3 and 6 , ring closure and intra-annular elimination of F occur in a one-step reaction and are the rate determining step due to the high barrier and strong endothermicity. Intra-annular elimination of $\mathrm{H}$ is the rate determining step for pathways 2,4 and 5 .

It is clear from Fig. 1 that intra-annular elimination of $\mathrm{H}$ involved in pathways 2, 4 and 5 are less endoergic than intraannular elimination of $\mathrm{F}$ involved in pathways 1,3 , and 6 because the $\mathrm{C}-\mathrm{F}$ bond is stronger than the $\mathrm{C}-\mathrm{H}$ bond. Thus, pathways 2, 4 and 5 are favored over pathways 1, 3 and 6 . Furthermore, the potential barriers of $\mathrm{H}$ abstraction involved in pathways 4 and 5 are lower than that of $\mathrm{F}$ abstraction involved in pathway 2. So, pathways 4 and 5 are favored over pathway 2. Hence, the thermodynamically favorable PFDD formation pathways are pathways 4 and 5. The resulting 1,9-DFDD and 1,6-DFDD are the main PFDD products, which differs from the PCDD formation from 2-CP and the PBDD formation from 2-BP ${ }^{20,31}$.

Formation of PFDFs: Three possible formation pathways of PFDF from 2-fluorophenoxy radicals are illustrate in Fig. 2. All PFDF formation pathways involve five elementary steps. Pathways 7 and 9 involve carbon-carbon coupling, H or F abstraction, tautomerization, and ring closure and elimination of $\mathrm{OH}$. Pathway 8 involves carbon-carbon coupling, tautomerization, $\mathrm{H}$ abstraction, ring closure, and elimination of $\mathrm{OH}$. The ring closure process is the rate determining step due to the high barrier and strong endothermicity. It can be seen from Fig. 2 that the formation of IM12 is less exothermic than the formation of IM11. Moreover, the rate determining step involved in pathways 7 and 8 have lower barrier and is less endothermic than that involved in pathway 9 . Thus the pathways 7 and 8 is favorable than pathway 9 , and the formation of 4,6-DFDF is preferred over the formation of 4-MFDF. Comparison of the thermodynamically favorable formation pathways of PFDD and PFDF shows that the formation of PFDD and PFDF from 2-fluorophenol are competitive. 


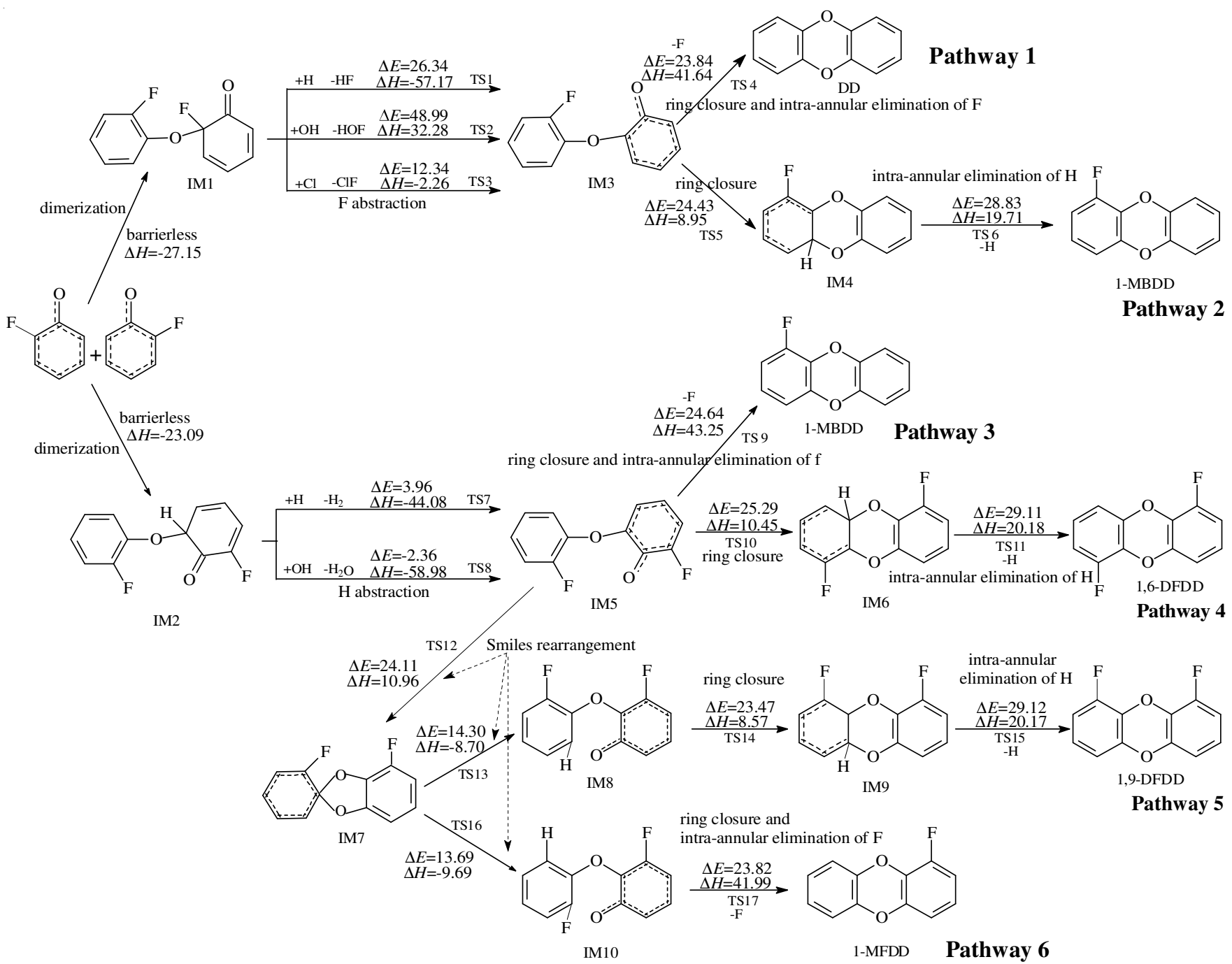

Fig. 1. PFDD formation routes embedded with the potential barriers $\Delta \mathrm{E}$ (in $\mathrm{kcal} / \mathrm{mol}$ ) and reaction heats $\Delta \mathrm{H}$ (kcal/mol, $0 \mathrm{~K}$ ) from 2 -fluorophenol as precursor

Rate constant calculations: The scarceness of the kinetic parameters, such as the pre-exponential factors, the activation energies and the rate constants, of the elementary reactions is the most difficult challenge in constructing the reaction kinetic model to predict the potential outcomes of PFDD/F releases to the environment. In this work, the rate constants of elementary reactions involved in the formation of PFDD/Fs from the 2-fluorophenol as precursor were calculated by the CVT theory

TABLE-1

ARRHENIUS FORMULAS $\left(\mathrm{s}^{-1}\right.$ AND $\mathrm{cm}^{3}$ molecule $\left.\mathrm{s}^{-1} \mathrm{~s}^{-1}\right)$ FOR UNIMOLECULAR AND BIMOLECULAR REACTIONS, RESPECTIVELY AND THEIR REGRESSION COEFFICIENTS $\left(R^{2}\right)$ FOR ELEMENTARY REACTIONS INVOLVED IN THE FORMATION OF PFDD/Fs FROM THE 2-FLUOROPHENOL PRECURSOR OVER THE TEMPERATURE RANGE OF 600-1200 K

\begin{tabular}{|c|c|c|}
\hline Reactions & Arrhenius formulae & $\mathrm{R}^{2}$ \\
\hline $2-\mathrm{FP}+\mathrm{H} \rightarrow 2-\mathrm{BRP}+\mathrm{H}_{2}$ & $\mathrm{k}(\mathrm{T})=\left(1.98 \times 10^{-11}\right) \exp (-4767.69 / \mathrm{T})$ & 0.9680 \\
\hline $2-\mathrm{FP}+\mathrm{OH} \rightarrow 2-\mathrm{FPR}+\mathrm{H}_{2} \mathrm{O}$ & $\mathrm{k}(\mathrm{T})=\left(7.90 \times 10^{-13}\right) \exp (-8743.93 / \mathrm{T})$ & 0.9505 \\
\hline $2-\mathrm{FP}+\mathrm{Cl} \rightarrow 2-\mathrm{FPR}+\mathrm{HCl}$ & $\mathrm{k}(\mathrm{T})=\left(2.73 \times 10^{-11}\right) \exp (-3876.47 / \mathrm{T})$ & 0.9721 \\
\hline $2-\mathrm{FP}+\mathrm{F} \rightarrow 2 \mathrm{FPR}+\mathrm{HF}$ & $\mathrm{k}(\mathrm{T})=\left(1.67 \times 10^{-12}\right) \exp (-4720.36 / \mathrm{T})$ & 0.9632 \\
\hline $\mathrm{IM} 2+\mathrm{H} \rightarrow \mathrm{IM} 5+\mathrm{H}_{2}$ & $\mathrm{k}(\mathrm{T})=\left(4.75 \times 10^{-12}\right) \exp (-15062.37 / \mathrm{T})$ & 0.9565 \\
\hline IM5 $\rightarrow$ IM6 & $\mathrm{k}(\mathrm{T})=\left(1.13 \times 10^{12}\right) \exp (-6450.03 / \mathrm{T})$ & 0.9727 \\
\hline $\mathrm{IM} 6 \rightarrow 1,6-\mathrm{DFDD}+\mathrm{H}$ & $\mathrm{k}(\mathrm{T})=\left(3.75 \times 10^{13}\right) \exp (-11235.43 / \mathrm{T})$ & 0.9811 \\
\hline IM5 $\rightarrow$ IM7 & $\mathrm{k}(\mathrm{T})=\left(3.24 \times 10^{12}\right) \exp (-9611.78 / \mathrm{T})$ & 0.9631 \\
\hline IM7 $\rightarrow$ IM8 & $\mathrm{k}(\mathrm{T})=\left(8.01 \times 10^{12}\right) \exp (-7144.61 / \mathrm{T})$ & 0.9887 \\
\hline IM8 $\rightarrow$ IM9 & $\mathrm{k}(\mathrm{T})=\left(4.34 \times 10^{11}\right) \exp (-33.2 .77 / \mathrm{T})$ & 0.9956 \\
\hline $\mathrm{IM} 9 \rightarrow 1,9-\mathrm{DFDD}+\mathrm{H}$ & $\mathrm{k}(\mathrm{T})=\left(1.89 \times 10^{11}\right) \exp (-10307.08 / \mathrm{T})$ & 0.9716 \\
\hline $\mathrm{IM} 11+\mathrm{H} \rightarrow \mathrm{IM} 14+\mathrm{H}_{2}$ & $\mathrm{k}(\mathrm{T})=\left(9.88 \times 10^{-11}\right) \exp (-1898.76 / \mathrm{T})$ & 0.9684 \\
\hline IM14 $\rightarrow$ IM15 & $\mathrm{k}(\mathrm{T})=\left(2.02 \times 10^{-12}\right) \exp (-7713.47 / \mathrm{T})$ & 0.9902 \\
\hline IM15 $\rightarrow$ IM16 & $\mathrm{k}(\mathrm{T})=\left(4.29 \times 10^{12}\right) \exp (-6530.11 / \mathrm{T})$ & 0.9510 \\
\hline $\mathrm{IM} 16 \rightarrow 4.6-\mathrm{DFDF}+\mathrm{OH}$ & $\mathrm{k}(\mathrm{T})=\left(7.97 \times 10^{11}\right) \exp (-13359.17 / \mathrm{T})$ & 0.9779 \\
\hline
\end{tabular}



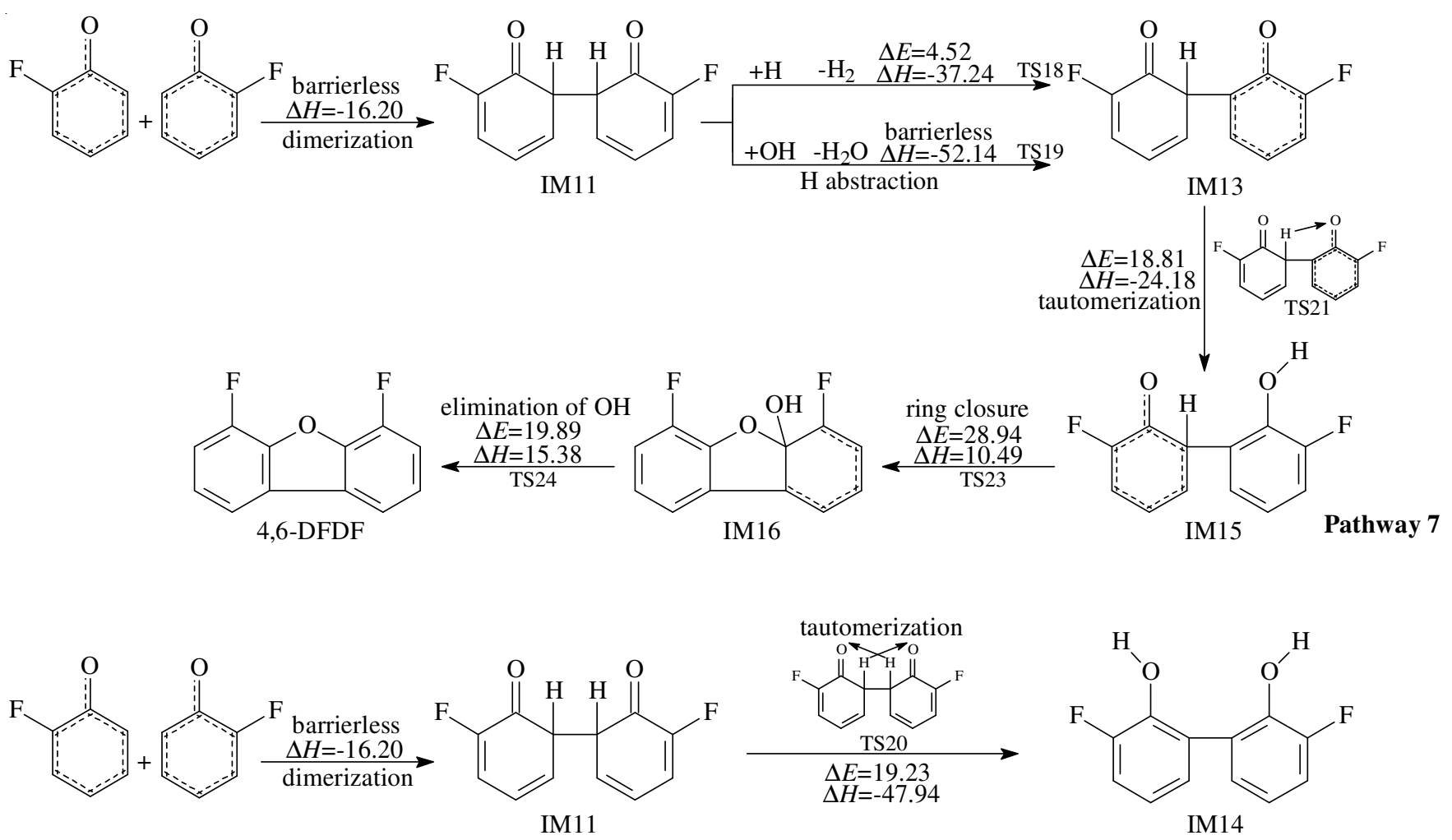<smiles>Oc1ccccc1-c1cccc(F)c1O</smiles>

IM14

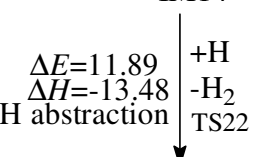<smiles>Fc1cccc2c1oc1c(F)cccc12</smiles>

4,6-DFDF

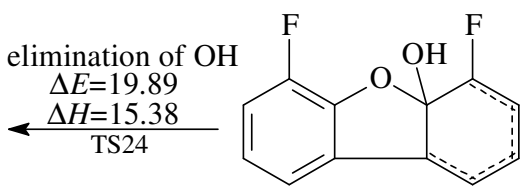

IM16

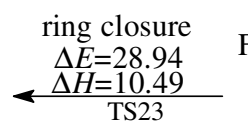<smiles></smiles>

IM15
Pathway 8

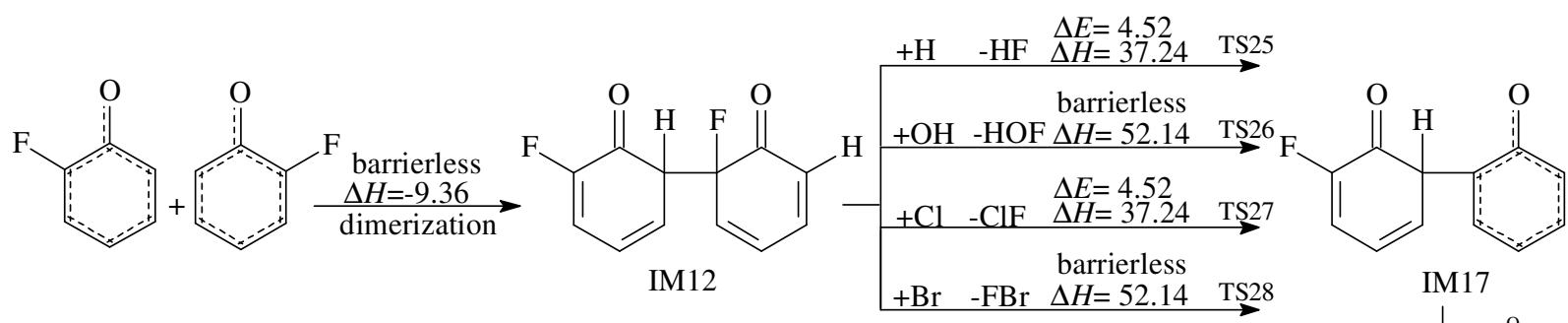

$\mathrm{H}$ abstraction

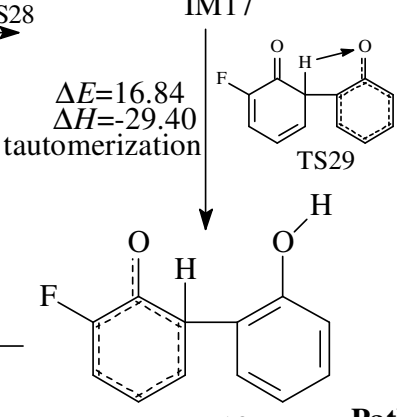<smiles>OC12C=CC=C(C1)c1cccc(F)c1O2</smiles>

IM19

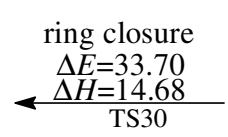

$\mathrm{IM} 18$
Pathway 9

Fig. 2. PFDF formation routes embedded with the potential barriers $\Delta \mathrm{E}$ (in $\mathrm{kcal} / \mathrm{mol}$ ) and reaction heats $\Delta \mathrm{H}$ (in $\mathrm{kcal} / \mathrm{mol}, 0 \mathrm{~K}$ ) from 2 -FP as precursor

with the SCT contribution over the temperature range of 600$1200 \mathrm{~K}$, which cover the possible formation temperatures of PFDD/Fs in the municipal waste incinerators or other high temperature industry processes. Previous studies ${ }^{24,32}$ have clarified the reliability of the CVT/SCT method. The calculated CVT/SCT rate constants are fitted and Arrhenuius formulas are listed in Table-1. The regression coefficients $\left(\mathrm{R}^{2}\right)$ of all the Arrhenius formulae are high $\left(R^{2}>0.95\right)$ indicate that the results are acceptable. 


\section{Conclusions}

In this paper, the formation of PFDD/Fs was theoretically investigated. 2-Fluorophenol has been selected as a model of fluorophenols. The rate constants of crucial elementary reactions were calculated by using the CVT/SCT method. Several specific conclusions can be drawn from our study:

(1) Thermodynamically favorable PFDD formation pathways occur via pathways 4 and 5.

(2) Formations of PFDDs and PFDFs are competitive.

(3) Theoretical calculations suggest that the main dioxin products from 2-fluorophenol are 1,6-DFDD, 1,9-DFDD, and 4,6-DFDF.

(4) Formation of PFDDs from fluorophenols is relatively more difficult compared to the formation of the analogous PCDDs from Chlorophenols and PBDDs from bromophenols.

\section{ACKNOWLEDGEMENTS}

This work was supported by NSFC (National Natural Science Foundation of China, Project Nos. 21337001 and 21177077) and Independent Innovation Foundation of Shandong University (IIFSDU, Project No. 2012JC030). The authors thank Prof. Donald G. Truhlar for providing the POLYRATE 9.3 program.

\section{REFERENCES}

1. R. Weber, D. Schrenk, H.J. Schmitz, A. Hagenmaier and H. Hagemnaier, Chemosphere, 30, 629 (1995).

2. S. Sakai, M. Hiraoka and K. Shiozaki, Organohalogen Compd., 23, 347 (1995)

3. B.D. Key, R.D. Howell and C.S. Criddle, Environ. Sci. Technol., 31, 2445 (1997)

4. Y. Liu, L. Ma, Y. Liu and G. Kong, Environ. Sci. Technol., 40, 6411 (2006).

5. J. Sanchez, F. Alloin and C. Iojoiu, J. Fluor. Chem., 127, 1471 (2006).

6. H. Hou, B. Chen, X. Zhang and Z. Wang, Acta Chim. Sin., 69, 617 (2011).

7. X. Yang, H. Liu, H. Hou, A. Flamm, X. Zhang and Z. Wang, J. Hazard. Mater., 181, 969 (2010).
8. P.H. Taylor, T. Yamada, R.C. Striebich, J.L. Graham and R.J. Giraud, Reprod. Toxicol., 33, 606 (2012).

9. D. Herzke, R. Thiel, W.D. Rotard and D. Neubert, Life Sci., 71, 1475 (2002).

10. T. Zhang, H.W. Sun, Q. Wu, X.Z. Zhang, S.H. Yun and K. Kannan, Environ. Sci. Technol., 44, 3572 (2010).

11. A.B. Lindstrom, M.J. Strynar and E.L. Libelo, Environ. Sci. Technol., 45, 7954 (2011).

12. R.E. Alcock and K.C. Jones, Environ. Sci. Technol., 30, 3133 (1996).

13. A. Yasuhara, T. Katami, T. Okuda, N. Ohno and T. Shibamoto, Environ. Sci. Technol., 35, 1373 (2001).

14. R. Addink and E.R. Altwicker, Environ. Sci. Technol., 38, 5196 (2004).

15. M. Teng, New Chem. Mater., 11, 1 (2002).

16. J. Shi, R. Qu, A. Flamm, H. Liu, Y. Xu and Z. Wang, Sci. Total Environ., 414, 404 (2012).

17. J. Iskra, S. Stavber and M. Zupan, Collect. Czech. Chem. Commun., 73, 1671 (2008).

18. W. Yu, J. Hu, F. Xu, X. Sun, R. Gao, Q. Zhang and W. Wang, Environ. Sci. Technol., 45, 1917 (2011).

19. F. Xu, W. Yu, R. Gao, Q. Zhou, Q. Zhang and W. Wang, Environ. Sci. Technol., 44, 6745 (2010).

20. Q. Zhang, S. Li, X. Qu, X. Shi and W. Wang, Environ. Sci. Technol., 42, 7301 (2008).

21. Y. Zhao and D.G. Truhlar, J. Phys. Chem. A, 108, 6908 (2004).

22. J. Zheng, Y. Zhao and D.G. Truhlar, J. Chem. Theory Comput., 5, 808 (2009).

23. C. Zhang, T. Sun and X. Sun, Environ. Sci. Technol., 45, 4756 (2011).

24. X. Sun, C. Zhang, Y. Zhao, J. Bai, Q. Zhang and W. Wang, Environ. Sci. Technol., 46, 8148 (2012).

25. B.C. Garrett and D.G. Truhlar, J. Phys. Chem., 83, 1052 (1979).

26. K.K. Baldridge, M.S. Gordon, R. Steckler and D.G. Truhlar, J. Phys. Chem., 93, 5107 (1989).

27. A. Fernández-Ramos, E. Martínez-Núñez, M.A. Ríos, J. RodríguezOtero, S.A. Vázquez and C.M. Estévez, J. Am. Chem. Soc., 120, 7594 (1998).

28. H. Landolt and R. Börnstein, Structure Data of Free Polyatomic Molecules, Springer (1992).

29. M.A.V.R. da Silva and A.I.M.C. Lobo Ferreira, J. Chem. Thermodyn., 41, 1104 (2009).

30. W. Malcolm and Jr. Chase, NIST-JANAF Themochemical Tables, Fourth Edition, Journal of Physical and Chemical Reference Data, Monograph 9, Washington, D.C. (1998).

31. W. Pan, D. Zhang, Z. Han, J. Zhan and C. Liu, Environ. Sci. Technol., 47, 8489 (2013).

32. Q. Luo and Q.S. Li, J. Phys. Chem. A, 108, 5050 (2004). 